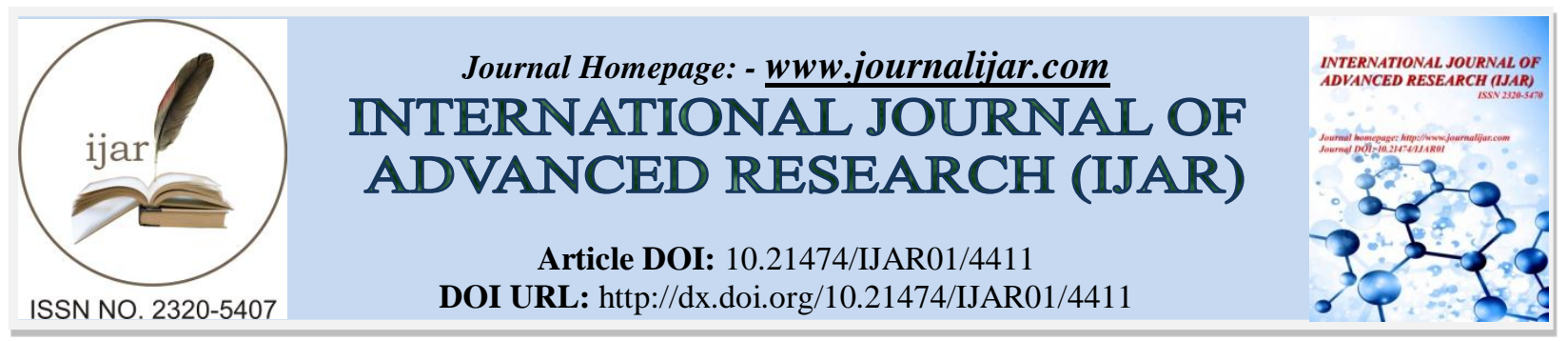

RESEARCH ARTICLE

\title{
CAST PARTIAL DENTURE WITH ATTACHMENT: BOON TO PREVENTIVE PROSTHODONTICS- A CASE REPORT.
}

Snehal Ashok Shende ${ }^{1}$, Swapneel Charandas Bodele ${ }^{2}$, Girish Kubasad ${ }^{3}$ and Abhijit Deshpande ${ }^{4}$.

1. MDS, Sr. Lecturer, Department of Prosthodontics, Tatyasaheb Kore Dental College \& Research Centre, Kolhapur.

2. MDS, PG Student, Department of Periodontology Tatyasaheb Kore Dental College \& Research Centre, Kolhapur.

3. MDS,HOD \& Professor, Department of Prosthodontics, Tatyasaheb Kore Dental College \& Research Centre, Kolhapur.

4. MDS. Professor, Department of Prosthodontics, Tatyasaheb Kore Dental College \& Research Centre, Kolhapur.

\section{Manuscript Info}

............

Manuscript History

Received: 07 April 2017

Final Accepted: 09 May 2017

Published: June 2017

Key words:-

Partial edentulism, Cast partial denture,

Precision Attachment.

\section{Abstract}

The demand and awareness for quality of dental treatment is relatively increasing in today's generation mainly aesthetics are concerned, along with other functions of the prosthesis. The most challenging job for a prosthodontist is to rehabilitate the partial edentulous patient especially distal extension cases where fabrication of fixed prosthesis is quite impossible without using implants. Several conventional and contemporary treatment options were available for treating long span edentulous situations In case of partially edentulous mouth, it requires more attention for esthetics. While achieving the goal, the components which are incorporated in removable partial denture may result in unsightly appearance. In this case report, precision attachment is used which amplified the aspects of retention stability and particularly esthetics when compared to conventional removable partial dentures.

Copy Right, IJAR, 2017,. All rights reserved.

\section{Introduction:-}

Esthetically and functionally successful prosthetic rehabilitation requires careful attention and meticulous treatment planning [Deshraj jain,2015]. Prosthetic rehabilitation of partially edentulous mouth involves diverse techniques for specific patients. Whatever treatment is planned, the final planning must offer the best solution suited to an individual patient rather than a solution which will be more contented for the operator [Harsh Patel,2014]. Partial edentuluous arch with distal exention classified under Kennedy class I \& class II situation can be difficult for their rehabilitation [McCraken's, 12 edtition]. In such a condition, a fixed partial denture cannot be fabricated because of missing distal abutment. We can plan for implant-supported prosthesis, but it is sometimes not economical or it is not feasible due to insufficient amount of bone. So, in such situation conventional partial denture or cast partial denture is mostly preferred.

A Cast Partial Denture with a retained attachment system is one of the best treatment among the various modalities to achieve better and aesthetic and prosthetic outcomes. An attachment is defined as "A mechanical device for the 
fixation, retention and stabilization of a prosthesis". Precision attachments could be extracoronal and intracoronal. Cast partial dentures with Attachment retainer deliver both aesthetic and functional replacement of missing teeth.

This case report describes a patient with mandibular bilateral distal extension Kennedy's class I condition which is prosthetically restored by a cast partial denture retained using a extracoronal castable precision attachment (RHEIN 83 OT CAP attachments system) with maxillary cast partial denture.

\section{Case Report:-}

A 50-year-old female reported with maxillary and mandibular partially edentulous arches with minimal resorption of maxillary and mandibular arch. On intraoral examination, it was noted that the patient had missing $14,15,16,22,23,25,26,33,34,35,36,37,44,45,46,47$ The remaining teeth in maxillary and mandibular arch were periodontally stable (Figure1).

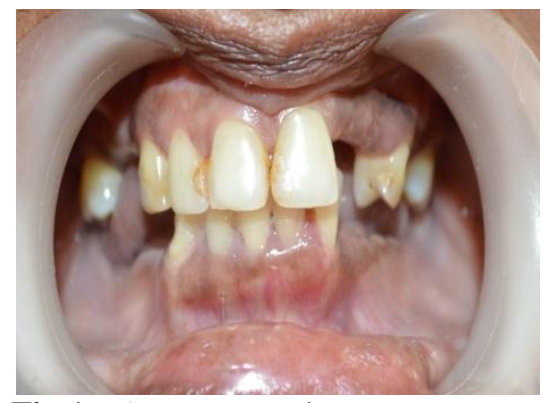

Fig.1:- A. Pre-operative Front View

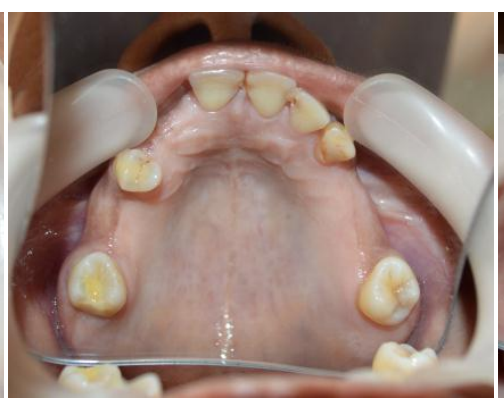

Fig.1:- B. Pre-operative Intraoral Maxillary View

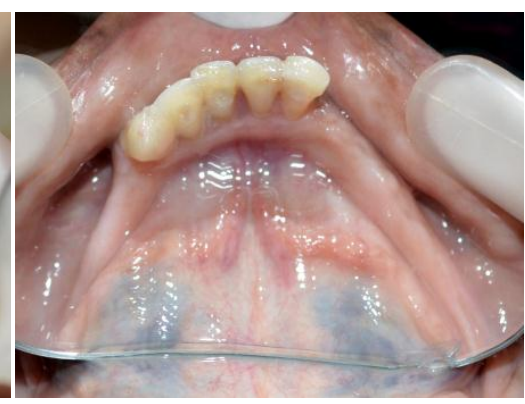

Fig.1:- C Pre-operative Intraoral Mandibular View

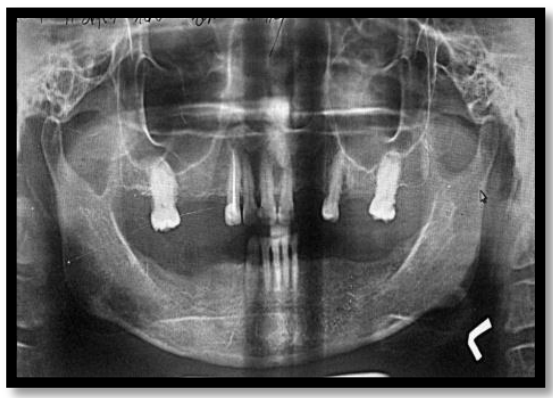

Fig.1:- D Pre-Operative OPG.

Diagnostic impression were made with irreversible hydrocolloid impression material.After that tentative jaw relation was made and diagnostic mounting was done to evaluate the interarch space.

After complete clinical and radiographic examination, a prosthetic treatment plan was set up. Combined prosthesis with extracoronal precision attachment was planned for mandibular bilateral distal extension arch and cast partial denture for maxillary arch.

Tooth preparation of numbers 31,32,41,42and 43 abutment teeth was performed and gingival retraction was done to receive porcelain fused to metal crowns (Figure2). After that jaw relation was made. 


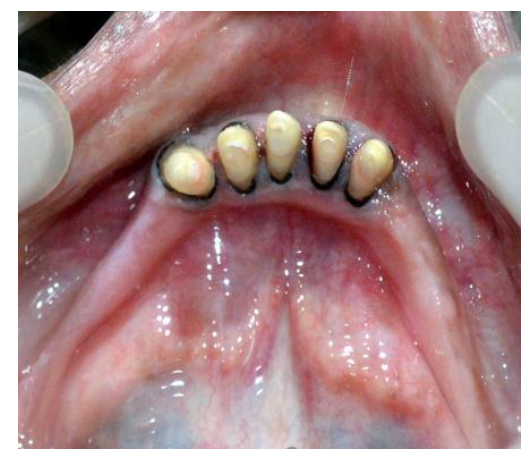

\section{Lab Procedure:-}

Waxing up of abutments 31,32,41,42and 43 was performed and milling of lingual area of metal ceramic setup was done. Articulation spaces and bulkiness were evaluated in order to proceed with optimal positioning of attachments using proper parallelometer mandrel.

\section{PFM Crowns with Attachment and Metal Framework Casting Trial:-}

Porcelain fused metal crowns waxed up with attachment structure were casted and porcelain firing was done. Joint crowns were fabricated with the attachments in the laboratory and the trial of the same was done to check the exact fit of the crowns.(Fig.3)

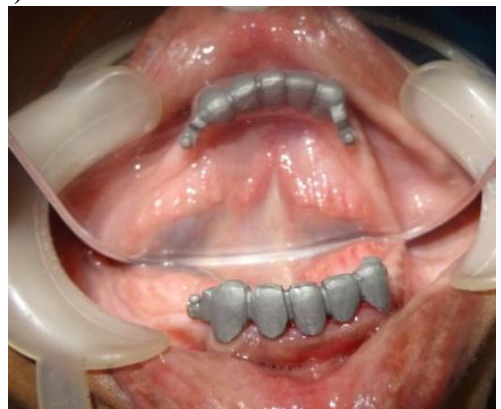

Fig.3 A. Metal Crowns With attachment

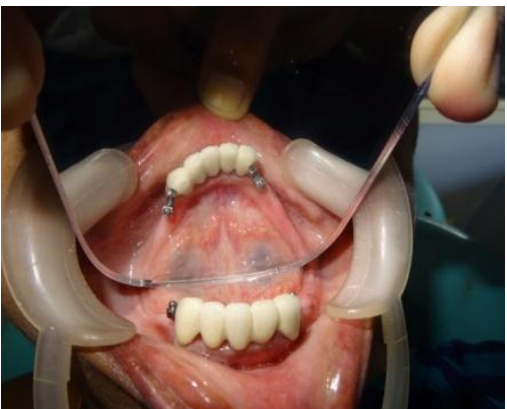

Fig 3:- B. PFM with attachment

Cast partial denture with attachment was fabricated in the laboratory Male attachment is kept $1 \mathrm{~mm}$ above the gingival to facilitate oral hygiene [Yen-Chen $\mathrm{Ku}, 2000]$ and the metal framework trial was done in the patient's mouth for the accuracy of fit (Figure 4). Metal cast structure framework was checked up for stability and precision fit and jaw relation were recorded. (Figure 5 ).

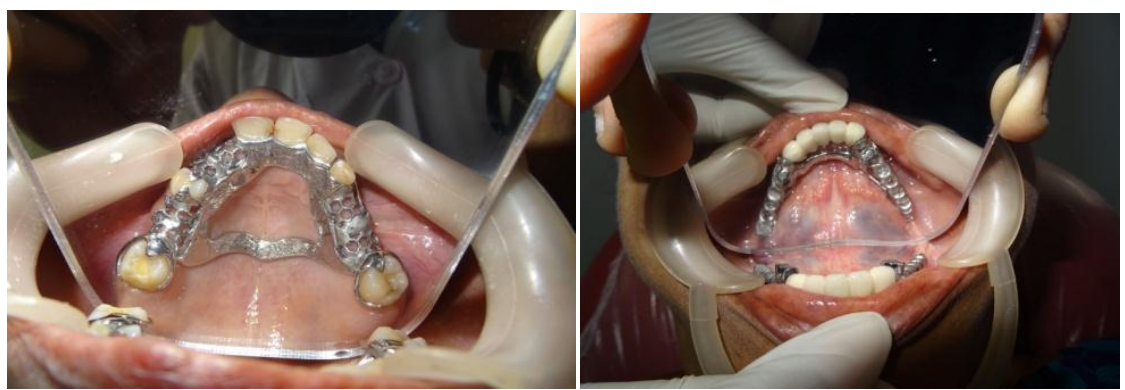

Fig. 4:- Metal Framework. 


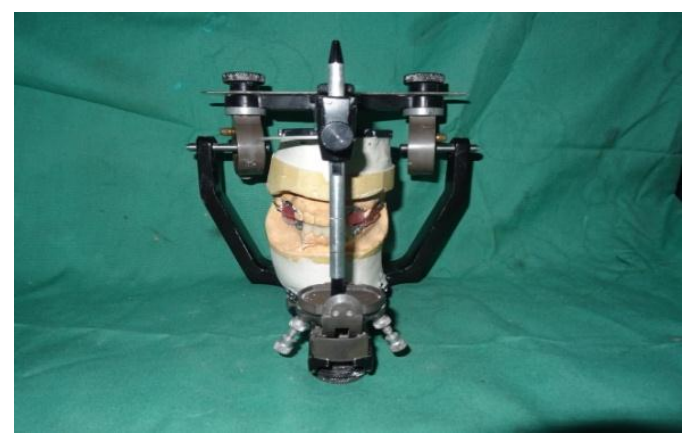

Fig 5:- Jaw Relation.

\section{Wax-Up Trial:-}

Waxing up of teeth was done and teeth setting trial were taken in patient's mouth (Figure 6 ). The trial denture were sent for acrylization and cast partial denture finished.

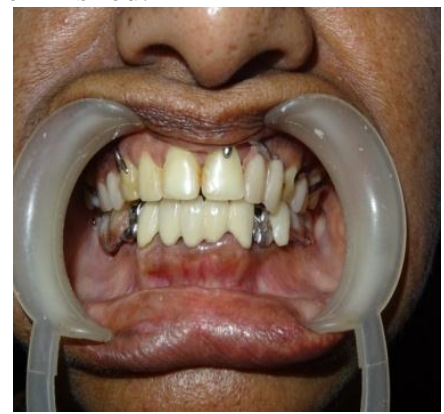

Fig .6:- Try In.

Positioning the Combined Prosthesis in the Patient's Mouth:-

Trial seating of the finished prosthesis were performed and cementation of crowns were done using Glass Ionomer cement (GC Fuji). Attachments are sheltered with a thin layer of petroleum jelly (Vaseline) in order to easily remove cast partial denture after joint PFM crowns with attachment have been seated. Complete seating of finished combined mandibular prosthesis with extracoronal castable distal extension precision attachment were evaluated clinically and maxillary cast partial denture were also seated in the patient's mouth (Figure 7 ) and the patient was recalled after $24 \mathrm{hrs}$ for post insertion checkup.

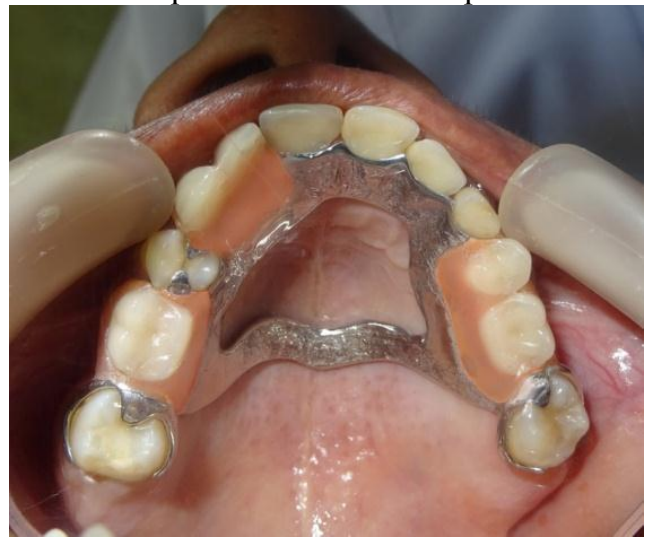

Fig.7 A.Post-operative Intraoral Maxillary View

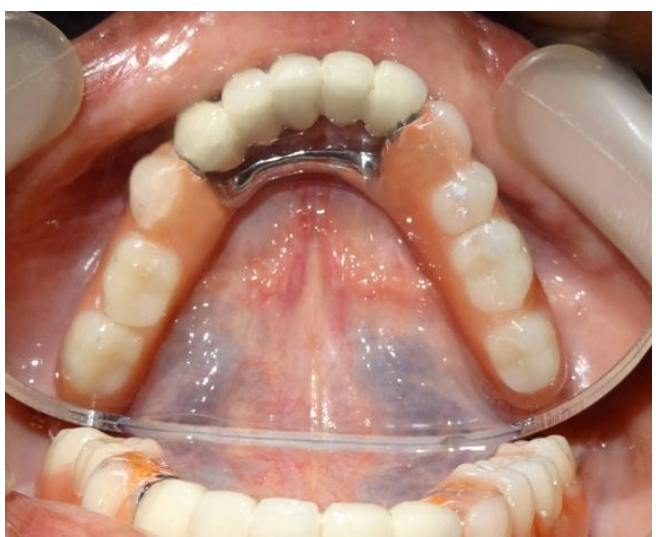

Fig.7 B. Post-operative Intraoral Mandibular View 


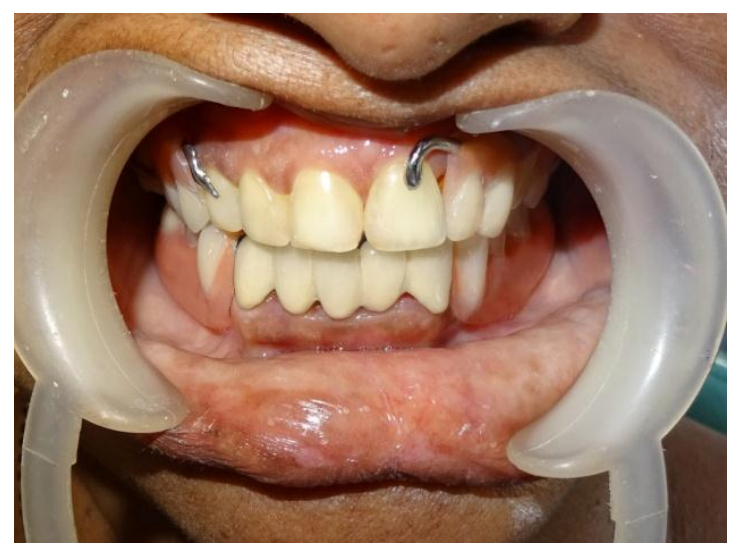

Fig.7 C. Final Prosthesis.

\section{Discussion:-}

There are several treatment options for the rehabilitation of partial edentulism. Depending on several given diagnostic factors and a patient's perspective, best treatment plan should be selected for the patient. In recent years, dentistry has witnessed the use of Computer aided design and Computer assisted milling (CAD-CAM) [William et al, 2005] , precision milled and semiprecision attachments, improved impression materials, improved techniques and designs which would eventually attain a comprehensive treatment. In case of partially edentulous mouth, Retention provided by the usage of precision attachments which may be related to comfort, satisfaction, chewing ability, as well as adequate distribution of occlusal loads to, and preservation of abutment teeth in patients with removable partial dentures. Retentive ability increases significantly over time in the metalalloy precision attachment group. Charkawi HG et al evaluated and quantified changes in retention ability and weight change over time and thus reported Metal-alloy and plastic inserts precision attachments preserve supporting teeth and alveolar bone ridges when associated with at least two splinted abutments [Charkawi HG,1996]. [Holst et al,1973] cited as it is difficult to evaluate precision attachments' effects on treatment longevity based solely on in vitro results since other factors such as continuous ridge resorption, changes in saliva flow and composition, and occlusal considerations may affects its long-term success.

In this case report, the RHEIN 83 OT CAP attachments system used in the case is extracoronal castable attachment positioned on the distal of the crowns as an extension. The castable OT CAP male can be easily shaped together with the crowns during waxing-up stage avoiding complicated adaptation procedures like welding a metal attachment after crown casting. The male component design is sphere with a flat head and female component is retentive nylon caps which are color-coded according to different retentive properties.

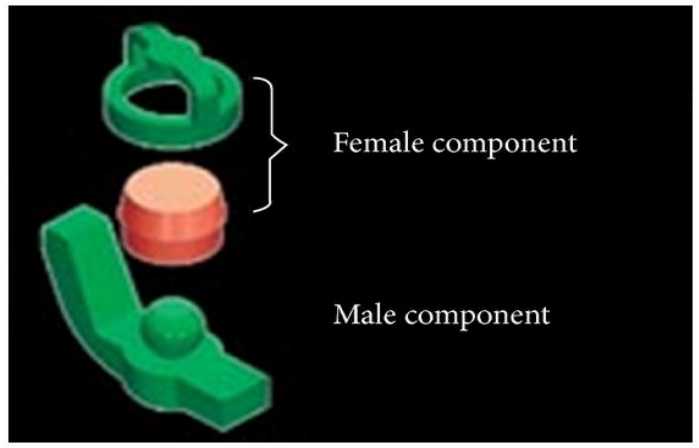

Fig.8. RHEIN 83 OT CAP attachments

Construction of such attachment require skill from dental technicians which cannot be acquired easily and needs training. The parts of the attachment are usually exposed to wear and tear and needed to be replaced over time 


\section{Conclusion:-}

Removable partial dentures still have better option for Kennedy's class I and class II conditions. If there is proper diagnosis and treatment planning then precision attachment such as RHEIN 83 OT CAP castable attachment system gives the better retention, stability, function. Only it requires proper followup after every 6 months. Attachments retention can be monitored and upgraded during time just replacing retentive caps into the framework of dentures for patients comfort and satisfaction.

\section{References:-}

1. Dr. Deshraj jain, Dr. Alka Gupta, Dr. Sneha Chhabra, Dr Ajay Sangwan. Prosthodontic Rehabilitation using Attachment Retained Overdenture- Case Reports, IOSR Journal of Dental and Medical Sciences.2015, 22790861(14),8

2. Harsh Patel,Kavan Patel, Shrusti Thummer, Ruchita K. Patel.Use of precision attachment and cast partial denture for long-span partially edentulous mouth - A case report. International Journal of Applied Dental Sciences 2014; 1(1): 22-25

3. McCraken's Removable partial denture prosthodontics 12th edition. Pg 12.

4. Yen-Chen Ku, Yu-Fu Shen, Chiu-Po Chan. Extra coronal resilient attachments in distal-extension removable partial dentures. Quintessence International 2000; 31(5):161-164

5. Willium RJ, Bibb R, Eggbeer D, Collis J. Use of CAD/CAM technology to fabricate a removable partial denture framework. J Prosthet Dent 2006; 96(2): 96-99.

6. Charkawi HG, Wakad MT. Effect of splinting on load distribution of extracoronal attachment with distal extension prosthesis in Vitro. J Prosthet Dent 1996; 76(3):315-320.

7. Holst S, Blatz MB, Eitner S, Wichmann M. In Vitro wear of different material combinations of intracoronal precision attachments. Int J Prosthodont 2006; 19(4):330- 332. 9. Merrill C. Mensor JR. Classification and selection of attachments. J prosthet dent 1973; 29(5): 494-497. 